\section{SOI: 1.1/TAS DOI: 10.15863/TAS International Scientific Journal Theoretical \& Applied Science}

p-ISSN: 2308-4944 (print) e-ISSN: 2409-0085 (online)

Year: $2018 \quad$ Issue: $01 \quad$ Volume: 57

Published: $15.01 .2018 \quad \underline{\text { http://T-Science.org }}$

SECTION 25. Technologies of materials for the light and textile industry.

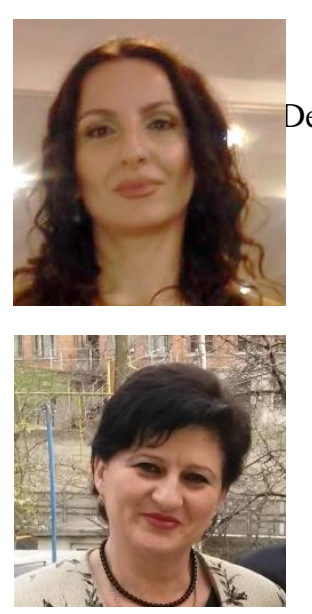

L.G. Kiknavelidze

PhD student, Teacher of the Department "Design and Technology",

Akaki Tsereteli State University, Kutaisi, Georgia

M.G. Grdzelidze

Doctor of Technical Sciences,

Professor of the Department

"Design and Technology",

Dean of Engineering Technological

Faculty of Akaki Tsereteli State

University, Kutaisi, Georgia

\title{
THE MODERN ASPECTS OF RESEARCH EVOLUTION OF GEORGIAN LEATHER ETHNO-CRAFTS
}

Abstract: The article discusses about the research problematics of Georgian ethno-items, especially the evolution of footwear, which is not perfectly studied yet. Competent study of this important part of the rich Georgian material culture as a result of epochal natural factor analysis will give us an opportunity of predicting and popularizing Georgian fashion, because, today, special attention is paid to the fashion directions where the culture and the history of the nation is displayed. This is the modern style garments with national elements, which always deserves the praise and recognition of viewers.

Key words: evolution of footwear; leather ethno-items; research of material culture; national fashion.

Language: English

Citation: Kiknavelidze LG, Grdzelidze MG (2018) THE MODERN ASPECTS OF RESEARCH EVOLUTION OF GEORGIAN LEATHER ETHNO-CRAFTS. ISJ Theoretical \& Applied Science, 01 (57): 29-32.

Soi: http://s-o-i.org/1.1/TAS-01-57-5 Doi: crossef https://dx.doi.org/10.15863/TAS.2018.01.57.5

\section{Introduction}

The footwear represents the important object of the workmanship of the human, because the normal functioning of the foot and whole body and everyday comfort of the human are dependent on the convenience of the shoes. The art of shoe-making requires the special high degree knowledge (anatomy-physiology of foot, material knowledge, construction-technology and etc.), fantasy and the specific characteristics of taste. Historically it's known, that the shoe-maker couldn't be the accidental person, he definitely must be the master of his job. This requires the high professionalism.

The leather items exhibited in Georgian museums or preserved in stores, the feudal sources about them, the frescoes and bas-reliefs remaining in cultic temples, miniatures in handwritings, iconographic and written sources, notices of foreign travelers aren't perfectly studied yet, they don't give us a clear image of the history of developing the construction of footwear and leather items in Georgia, correspondingly,

The insufficient information about the Georgian ethno-items isn't the only reason why those items are remained in very less amounts compared to other material heritages, but the main reason is the shortage of the professionals of this field. The analyses of leather items require not only the knowledge and experience in the direction of ethnologic and archeologic direction, but also the knowledge and skills in the field of footwear and leather product research. The necessity of it is stipulated by the multilateral (material knowledge, construction, technological and etc.) complexity of this items.

\section{Materials and Methods}

There are no many professionals with the specialty of footwear design, construction and technology. The study of the footwear evolution requires the high competence. The complete image about it can't be created with only the description of outward appearance if it, because the footwear and leather crafts belongs to the complex items according to constructional, technological and utilitarian point of view $[1,2,3]$. Herewith, the work is complicate by the fact that the majority of the remained leather products are damaged because of the age, this is because they are made from the natural leather, which as an organic material undergoes the decomposing and destruction process along the time (despite of the quality of the processing of the leather 
or the storing conditions). The time impacts negatively on the leather items.

We, the researchers of this issue, have set the goal to use all the existing means, material and source to study the evolution stages and regular factors of the Georgian ethno-footwear, leather accessories and crafts [4-7]. With this it will be possible to shed light to the history of this unstudied field of the Georgian material culture.

The preliminary studies conducted around this raised question revealed that ethno-materials are bulk in volume and the systematizing of this materials, ranking of the typical factors and clustering the epochal information about the evolution stages haven't been conducted yet.

Our team studies the remaining samples of the Georgian material culture on the territory of Georgia and abroad. Searching for all possible sources, recording the exponents, studying on a scientific level, systemizing and analyzing, using the traditional and modern methods of research will give us an ability to study the regularities of historical development of Georgian material culture in respect of leather crafts. This will enable gathering them in the form of catalogue. The research process is hard, but the result will be very interesting from the standpoint of the fact that the materials reflecting the result of the research will shed a light to this concrete field of the cultural past of the country. This will support the enhancement of consciousness and intellect in respect of Georgian material culture.

To reach the goals the research objective is:

- Collecting the remaining materials and their clustering according to evolution stage, epochal and regular properties and their analysis with the usage of modern methods of research (heuristicalorganoleptic, dialectic, grapho-analytical, statistical, instrumental and other; adequate to needs);

- Systematization of materials as a result of analysis, ranging of typical factors and their comparison in order to optimize the epochal information;

- Analysis of types of materials, and the methods of processing them;

- The cause-result analysis and regulatory studies of items and the construction of its separate detail, technology and evolution of production means the between the development stages of it.

- On each stage of evolution to illustrate the restored visual shape of existing leather item samples or sources with the artistic-constructive-technological descriptions;

- Predicting the vogue and construction of Georgian ethno item, on the basis of stepping changes of leather item display and construction (as an illustrated journal of ethno shoe and accessories).

The catalogue will be interesting as for wide circle of the society, also for the tourists. Especially, for this period, it will be the perfect catalogue of existed materials about leather items through Georgia. Most importantly it will be the first perfect research about the leather items to the scale of Georgia.

In order to understand and show the shore construction evolution properly and systemize evolution scheme of the imprtant part of the Georgian material culture - the construction of the leather items and production means and. it is important to find right, initial statute, which will get the concomitant basis of whole discussion, as here it is discussed the whole historical process from the ancient times up to now (in the limits of the available historical materials).

A human is permanently in touch with such complicated system, as it is an environment, so all samples, which will be found during the process, will be studied in system - "human-subjectenvironment". It is natural, that as an initial statute will be taken the laws of dialectics.

For the analysis of stageal characteristics of changing constructional and technological peculiarities of workmanships, and for analysis of epochal regularities and the dinamics of production means and geographical -social-economical factors of the materials, we use:

- Traditional and modern methods of research of the archaeological and ethnographic material heritage;

$\square$ Heuristical-organoleptic, physical-mechanical, physical-biological and instrumental methods of establishing the type, style, shape, color, types and characteristics of used materials for surface, bottom and auxiliary ones;

$\square$ With using graph-analytical method the analyses are conducted: of the construction, detail cut off, detail connection methods and means, visible edge process methods, methods and means for shoe surface connection to the bottom linked to the consumer-utilitarian characteristics of the item and social factors;

$\square$ Study with cause and effect analysis of inserting separable footwear details (sole, heel, insole and others) in the construction, detail quantity changes of the separable details, construction of the suture connecting them;

$\square$ We use statistical methods for analyzing the data in the processing of research results. In particular: the change of the shape and sizes of details, distribution of dinamic factors and distribution density according the epochs. We systemize regular factors, ranging the interconnected and mutual effect factors and conduct the cause-result analyses of them;

$\square$ The cyclical analyses of the visual-constructionaltechnological characteristics of the staging-regular factors in the evolution process is conducted with the purpose of constructing the regularity scheme;

- We use wide spread of analytical methods in the researche process and modern computer methods 
of regular factor analysis respectively. With the help of them using laws of dialectics and evolution we consuct the analysis of leather crafts, especially the visual of the footwear, construction, means of producing and dynamics of qualitative-utilitarian characteristics;

- It is interesting to cause-result analyse the impact of other country's culture, historical events, Silk Way and other factors on the Georgian ethnocrafts.

We use multiple abilities of modern digital technologies for visualizing the research results. After the disclosure of the research result the world will introduce the Georgia from the side of leather crafts evolution too and one more aspect of rich Georgian material culture will become known and available for the society.

Nowadays the national-traditional elements are noticeable more in clothing, than in the footwear. The national costumes are used only with special purpose - mainly by the Georgian ensembles. We often meet folk and ethnographic compositions during the creation of souvenirs for tourists. It is necessary to return to the rich folk heritage in the modern fashion collections. Nowadays, great attention is paid to the fashion directions, which reveals and demonstrates the culture and the history of the nation. Modern clothing created with using of national elements looks especially interesting. The show of the footwear and clothing of Georgian style and created on the Gerorgian national motives has taken place three times already on the competition of the Ukrainian young designers and has gained the common recognition of the viewers. This kind of shows is already the type of tradition in Georgia (Fig. 1).

Detail study and analysis of historical aspects of the footwear and leather crafts evolution will give us an opportunity to poplurarize ethno-style in the modern leather crafts. With the help of this, in parallel to the International style there will exist Georgian style, which may get and spread on international arena with its originality, like Georgian clothes, Georgian songs, dances and soon.

\section{Conclusion}

The technical progress has changed the products, made with the primitive tools into the industrial ones. As a result, production of unique ethno products almost fully stopped. These products meet us only in one units. The life has raised the question of necessity of renovation of everything national, traditional and historical. Young generation has avant-garde, individual, creative approach to the making clothing and this almost excludes the existence of the standards. It is impossible to stop this process, like stopping the time and human thinking, because by the nature the human always aspires to the renovation and perfection, so it is possible to manage this phenomenon by studying and guiding the regularities of the development for personal use items.
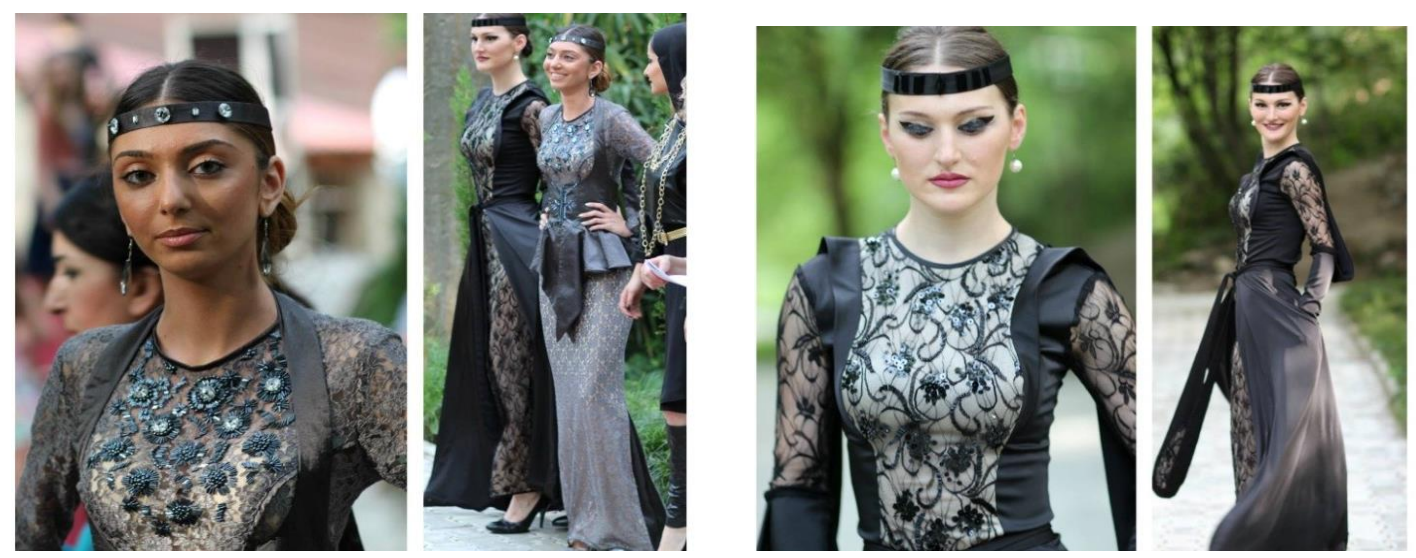


\begin{tabular}{l|lrl|l|ll} 
& ISRA (India) & $=\mathbf{1 . 3 4 4}$ & SIS (USA) & $=\mathbf{0 . 9 1 2}$ & ICV (Poland) & $=\mathbf{6 . 6 3 0}$ \\
Impact Factor: & ISI (Dubai, UAE) $=\mathbf{0 . 8 2 9}$ & PUHI (Russia) $=\mathbf{0 . 2 0 7}$ & PIF (India) & $=\mathbf{1 . 9 4 0}$ \\
& GIF (Australia) & $\mathbf{0 . 5 6 4}$ & ESJI (KZ) & $=\mathbf{4 . 1 0 2}$ & IBI (India) & $\mathbf{= 4 . 2 6 0}$
\end{tabular}
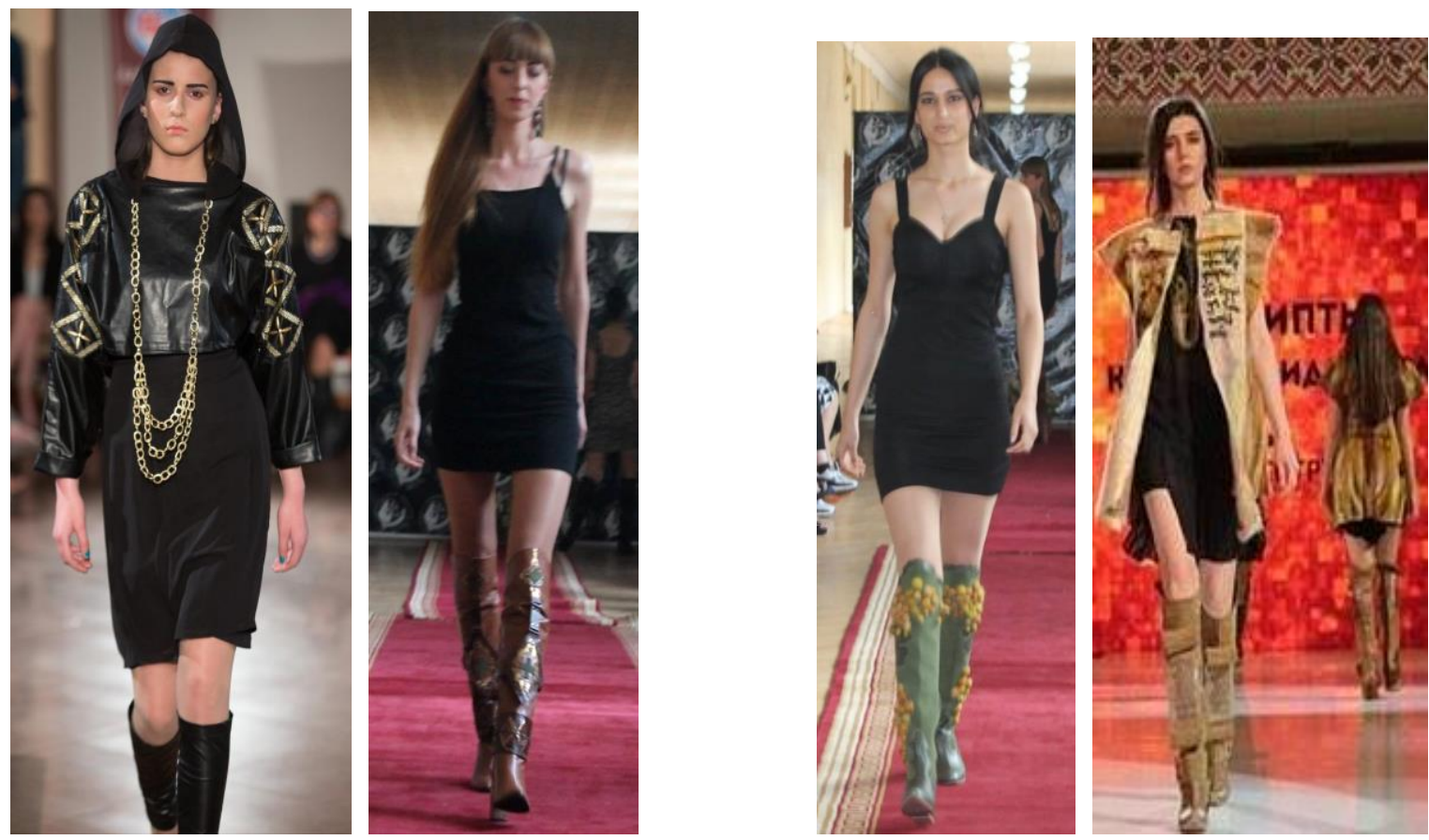

Fig. 1. The fragments from show of footwear and clothing created with national motives.

\section{References:}

1. Grdzelidze M. (2017) Statistical evaluation and analysis of the results of shoes wear test method for a pilot study. Magyar Tudományos Journal. (Budapest, Hungary) \#11. 2017. p: 30-34. Available: $\quad$ http://magyarjournal.com/en/magyar-tudomanyos-journal/.

(Accessed: 10.01.2018).

2. Grdzelidze M. (2017) The research of trauma correction of sportsmen foot and means of prevention of it. SCIENTIFIC ENQUIRY IN THE CONTEMPORARY WORLD: THEORETICAL BASICS AND INNOVATIVE APPROACH. B\&M Publishing Research and Publishing Center «Colloquium». San Francisco, California. L_26. 2017. p. 120124. DOI: http://doi.org/10.15350/L 26/10/5. Available: http:// Chopikashvili www.colloquium-

publishing.ru/1_doc/L_26 10.pdf. (Accessed: 10.01.2018)

3. Grdzelidze M. (2017) The problem of dimensional typology of the foot for the normal functioning of the musculoskeletal system. The Scientific journal "Norwegian Journal of development of the International Science”. \#5. part 2. Available: http://www.njdiscience.com/wp-

content/uploads/2017/04/NJD_5_2.pdf

(Accessed: 10.01.2018).

4. (2018) The Trialeti Silver Cup, 1 Millennium, is exhibited at the Exhibition of Simon Janashia Museum of Georgia - "Archaeological Treasures".

5. (2014) Metal-sculpture. National Treasure. Forum - Art.

6. Ivane Javakhishvili (1970) History of Georgian Nation. Tbilisi State University, Tbilisi, t. 1-5. p. 8-37.

7. Khoshtaria N. (1970) "Archaeological Monuments of the Antique epoch in Western Georgia" Archeology of Georgia. Tbilisi. p. 247.

8. (1973) Essays on Georgian History, vol. II (Georgia IV-XI centuries). Tbilisi. p. 506.

9. Sulkhan-Saba Orbeliani (1970) Dictionary Georgian. Tbilisi. t. 2, p. 31.

10. Georgian N. (1964) Costume.. Tbilisi. p. 142. 